\title{
Synthesis and Plane Selective Spin Trapping of a Novel Trap 5,5-Dimethyl-3-(2-ethoxycarbonylethyl)-1-pyrroline N-oxide
}

\author{
Yong-Kang Zhang*, Dao-Hui Lu, and Guang-Zhi Xu \\ National Laboratory for Structural Chemistry of Unstable and Stable Species, \\ Institute of Chemistry, Academia Sinica, Beijing 100080, China
}

Z. Naturforsch. 45b, 1075-1083 (1990); received November 16, 1989

5,5-Dimethyl-3-(2-ethoxycarbonylethyl)-1-pyrroline N-Oxide, Nitrone, Spin Trap,

Plane Selective Spin Trapping, EPR Spectra

A novel cyclic nitrone spin trap 5,5-dimethyl-3-(2-ethoxycarbonylethyl)-1-pyrroline $\mathrm{N}$-oxide has been prepared and its ability to trap a series of transient free radicals has been investigated. This nitrone scavenges free radicals to give persistent nitroxides, e.g., the half life-times of hydroxyl radical adducts and tert-butoxy radical adducts in benzene $>30 \mathrm{~min}$, and the life-time of acetyl adducts $>60 \mathrm{~min}$. The EPR spectrum of 2,2-dimethyl-4-(3-hydroxypropyl)pyrrolidinyl-1-oxyl aminoxyl shows that the hyperfine splitting constants of two $\beta$-hydrogens are equal to $14.58 \mathrm{G}$ and $23.29 \mathrm{G}$ respectively, i.e., the two $\beta$-hydrogens are not magnetically equivalent. Radical addition to the nitrone is probably plane selective affording only one of the two possible geometric isomer pairs of the spin adduct nitroxides. The trans approach mechanism is proposed through configuration and conformation analysis.

\section{Introduction}

The electron spin resonance trapping technique [1-3], or called spin trapping, has been widely used to study transient free radicals in various systems [4-11]. Spin traps play a very important role in this technique (eq. (1)).

$$
\mathrm{R}^{\cdot}+\operatorname{spin} \text { trap } \rightarrow \text { spin adduct }
$$

For the technique to work well, the trap should efficiently scavenge free radicals and afford persistent spin adducts of which the longer the life-times are, the better the spin trap is. Recently, 5,5-disubstituted-1-pyrroline N-oxides [12-16], 3,3,5,5-tetrasubstituted-1-pyrroline $\mathrm{N}$-oxides [17-19], and 3,3,4,5,5-pentasubstituted analogues [20] have been demonstrated to be good spin traps. In addition, an asymmetric carbon on the 5-ring position can induce stereospecific radical addition $[12,13$, 17]. We believe that a chiral carbon center on the $\mathrm{C}_{3}$ ring position adjacent to the nitronyl carbon should have much greater influence on radical addition stereoselectivity or stereospecificity and on the hyperfine splitting constants (hfsc) of the spin adduct $\beta$-hydrogen. In order to search for very efficient traps and to study spin trapping stereochemistry and radical stereochemical properties, 5,5-dimethyl-3-(2-ethoxycarbonylethyl)-1-pyrro-

* Reprint requests to Dr. Yong-Kang Zhang.

Verlag der Zeitschrift für Naturforschung, D-7400 Tübingen 0932-0776/90/0700-1075/\$01.00/0

line $\mathrm{N}$-oxide (4), in which the 3-carbon is a chiral center, was prepared according to the route illustrated in Scheme 1. Aldehyde-enamine alkylation ability is usually weaker than ketone-enamine's. The presence of $\mathrm{Me}_{2} \mathrm{CNO}_{2}$ group substitution much more decrease the alkylation ability of enamine $\mathbf{2}$ with ethyl acrylate, and so the yield was

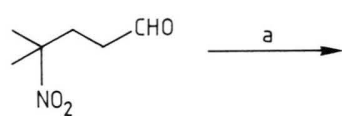

1

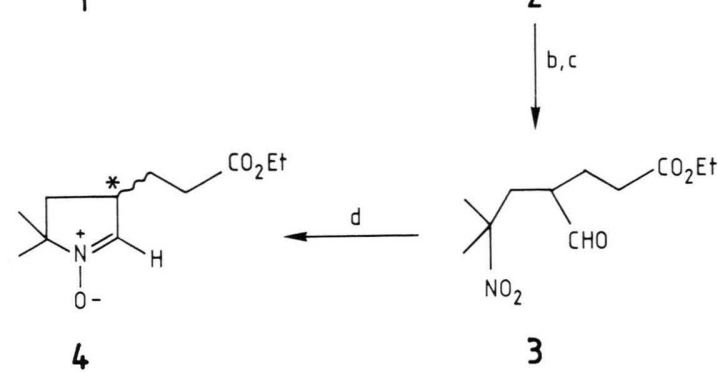

(a) piperidine, $\mathrm{K}_{2} \mathrm{CO}_{3}$ in $\mathrm{CH}_{3} \mathrm{CN}$; (b) $\mathrm{CH}_{2}=\mathrm{CHCO}_{2} \mathrm{Et}$ in $\mathrm{CH}_{3} \mathrm{CN}$; (c) $\mathrm{AcOH}, \mathrm{H}_{2} \mathrm{O}$; (d) $\mathrm{Zn} / \mathrm{ACOH}$ in $95 \% \mathrm{EHOH}$.<smiles>CC1(C)CCC=C1[O-]</smiles>

DMPO 
very low. In this paper, we also wish to report the spin trapping results with $\mathbf{4}$ and the plane selectivity of radical addition reactions in its spin trapping processes.

\section{Results and Discussion}

The nitrone $\mathbf{4}$ is soluble in water as well as in ordinary organic solvents. Therefore, nitrone 4 can be used to probe short-lived free radicals not only in organic phases but also in aqueous systems. The hfs constants of the spin adducts are presented in Table I while several typical EPR spectra are shown in Fig. 1.
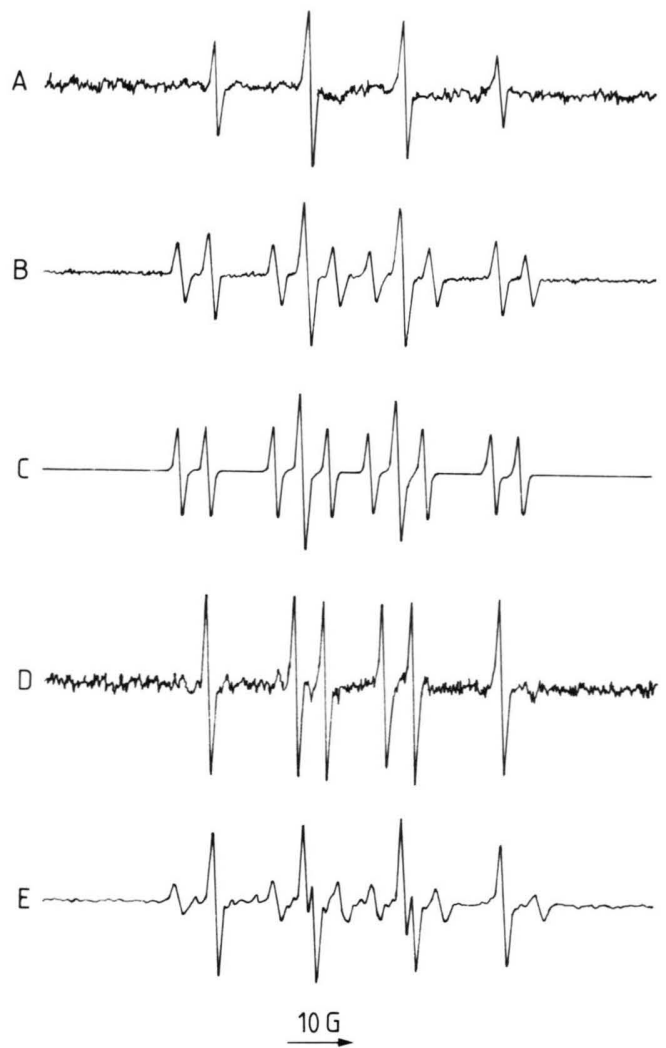

Fig. 1. EPR spectra of (A) hydroxyl spin adduct of $\mathbf{4}$ obtained by photolysis of zinc oxide and $\mathbf{4}$ in water; (B) hydroxyl and hydroxymethyl spin adducts of $\mathbf{4}$ obtained from photolysis of zinc oxide, methanol and $\mathbf{4}$ in water; (C) hydroxyl and $\dot{\mathrm{CO}}_{2}^{-}$spin adducts of $\mathbf{4}$ obtained by photolysis of zinc oxide and sodium oxalate in water; (D) $\mathrm{SO}_{3}^{-}$spin adduct of $\mathbf{4}$ obtained from photolysis of zinc oxide, sodium sulfite and $\mathbf{4}$ in water; (E) acetyl (high), and carboxymethyl and/or methyl (low) spin adducts of $\mathbf{4}$ obtained when photolysis of zinc oxide, acetic acid and $\mathbf{4}$ in water. Splitting parameters, see Table I.

\section{Spin trapping ability test}

The photolysis of zinc oxide in water can generate hydroxyl radicals [21, 22] (eq. $(2,3))$.

$$
\begin{aligned}
& \mathrm{ZnO} \stackrel{\mathrm{h} v}{\longrightarrow} \mathrm{ZnO}^{+}+\mathrm{e}^{-} \\
& \mathrm{ZnO}^{+}+\mathrm{H}_{2} \mathrm{O} \rightarrow \mathrm{OH}^{-}+\mathrm{ZnO}+\mathrm{H}^{+}
\end{aligned}
$$

In the presence of $\mathbf{4}$, the observed EPR spectrum showed a $1: 2: 2: 1$ pattern of four peaks which can be interpreted in terms of equivalent hyperfine splitting from both the $\beta$-hydrogen and the aminoxyl nitrogen atom $\left(a_{\mathrm{N}}=a_{\mathrm{H}}^{\beta}=15.53 \mathrm{G}\right)$. Such a $1: 2: 2: 1$ quartet of EPR signals was given when hydroxyl radicals were trapped respectively with $5,5-$ dimethyl-1-pyrroline N-oxide (DMPO) [16, 17, 21-26], 3,3,5,5-tetramethyl-4-ethoxycarbonyl1-pyrroline N-oxide (TMEPO) and its bispiroanalogue [20]. At the same condition, the $1: 2: 2: 1$ pattern of EPR spectrum was also resulted when DMPO was used as spin trap to replace nitrone 4. All these results support the assignment that the observed $1: 2: 2: 1$ quartet EPR spectrum is due to the trapping of hydroxyl radicals by nitrone 4 . Photolysis of zinc oxide dispersion in aqueous alcohols, such as methanol, ethanol, $n$-propanol, $n$-butanol, and in aqueous solution of $\mathrm{Na}_{2} \mathrm{C}_{2} \mathrm{O}_{4}$, $\mathrm{CH}_{3} \mathrm{CO}_{2} \mathrm{Na}, \mathrm{CF}_{3} \mathrm{CO}_{2} \mathrm{Na}$, and acetonitrile, respectively, in the presence of 4 afforded the 1:2:2:1 pattern EPR signals of hydroxyl adducts besides other signals. In benzene, spin trapping with $\mathbf{4}$ when photolysis of tert-dibutyl peroxide (DBPO), or the mixture of bromoethane with DBPO also gave the hydroxyl adduct four peaks besides the tert-butoxy adduct signals (eqs. $(4,5))$.

$$
\begin{aligned}
& \left(\mathrm{Me}_{3} \mathrm{CO}\right)_{2} \stackrel{\mathrm{h} v}{\longrightarrow} 2 \mathrm{Me}_{3} \mathrm{CO}^{\circ} \\
& \mathrm{Me}_{3} \mathrm{CO}+\mathrm{H}_{2} \mathrm{O}(\text { trace }) \rightarrow \mathrm{Me}_{3} \mathrm{COH}+\mathrm{OH}^{-}
\end{aligned}
$$

As listed in Table I, hfs constants of hydroxyl adducts are varied from $15.01 \mathrm{G}$ to $15.77 \mathrm{G}$ in different aqueous solutions, and equal to $c a .13 .50 \mathrm{G}$ in benzene solutions. The phenomenon that hfs constants of a same spin adduct are differing with different systems and different solvents is very common. For example, the hydroxyl adducts of DMPO in water employed various hfs constants from $14.77 \mathrm{G}$ to $15.3 \mathrm{G}$ refering to the systems in which radicals were trapped [23-26]. The solvent polarity can change the distribution of the unpaired spin density on nitroxyl group: 


$$
\text { ; }
$$

small hfsc large hfsc

A solvent with larger polarity such as water introduces the polarization of the nitroxyl group to increase the spin density on the nitrogen atom resulting the increase of hfs constants of spin adducts. Therefore, it is reasonable that the hydroxyl adduct hfs constants are larger in water than in benzene.

In zinc oxide dispersion in water, the hydroxyl adduct hfs constants of nitrone $\mathbf{4}$ and DMPO are respectively $15.53 \mathrm{G}$ and $14.90 \mathrm{G}$. The difference is due to their structural variation. For examples, the hfs constants of DMPO hydroxyl adducts in aqueous hydrogen peroxide were $14.8 \mathrm{G}$ for $a_{\mathrm{N}}$ and $a_{\mathrm{H}}^{\beta}$ while these of 3,3,5,5-tetramethyl1-pyrroline N-oxide (TMPO) hydroxyl adducts were $15.5 \mathrm{G}$ for $a_{\mathrm{N}}$ and $16.6 \mathrm{G}$ for $a_{\mathrm{H}}^{\beta}$ [17]; photolysis of $1 \% \mathrm{H}_{2} \mathrm{O}_{2}$ in phosphate buffer, the hfs con- stants of TMEPO hydroxyl adducts were $15.5 \mathrm{G}$ for $a_{\mathrm{N}}$ and $a_{\mathrm{H}}^{\beta}$ while these of TMEPO analogue hydroxyl adducts were $14.7 \mathrm{G}$ at the same condition [20]; the hfs constants were $15.8 \mathrm{G}$ for 5-methyl5-n-butyl-1-pyrroline $\mathrm{N}$-oxide hydroxyl adducts and $14.9 \mathrm{G}$ for 5,5-di- $n$-propyl-1-pyrroline $\mathrm{N}$ oxide hydroxyl adducts [16]. The reason is that different substitutions on the five-membered ring can change the preferential conformation of spin adduct aminoxyl ring resulting the changing of the $\mathrm{C}-\mathrm{H}_{\beta}$ orientation with respect to the semi-occupied $p$-orbital of aminoxyl nitrogen and the changing in distribution of unpaired spin density on nitroxyl group and nearby atoms.

The hydroxyl adducts of nitrone $\mathbf{4}$ were very stable and their intensities of the EPR signals were almost same within $30 \mathrm{~min}$ in benzene solution.

The photolysis of zinc oxide dispersed in the mixture of water and alcohol is the source of hydroxyalkyl radicals [22] (eq. $(6,7))$ which can be

\begin{tabular}{|c|c|c|c|c|c|}
\hline Source $^{b}$ & Radical addend & Solvent & $a_{\mathrm{N}}$ & $a_{\mathrm{H}}^{\beta}$ & $a_{\mathrm{H}}^{\gamma}$ \\
\hline $\mathrm{ZnO}+\mathrm{H}_{2} \mathrm{O}$ & $\mathrm{OH}$ & $\mathrm{H}_{2} \mathrm{O}$ & 15.53 & 15.53 & \\
\hline $\mathrm{ZnO}+\mathrm{CH}_{3} \mathrm{OH}+\mathrm{H}_{2} \mathrm{O}$ & $\begin{array}{l}{ }^{\cdot} \mathrm{CH}_{2} \mathrm{OH} \\
{ }_{\mathrm{OH}}\end{array}$ & $\mathrm{H}_{2}^{2} \mathrm{O}$ & $\begin{array}{l}15.86 \\
15.77\end{array}$ & $\begin{array}{l}25.58 \\
15.77\end{array}$ & \\
\hline $\mathrm{ZnO}+\mathrm{EtOH}+\mathrm{H}_{2} \mathrm{O}$ & $\begin{array}{l}\cdot \mathrm{CH}(\mathrm{OH}) \mathrm{CH}_{3} \\
\cdot \mathrm{OH}\end{array}$ & $\mathrm{H}_{2} \mathrm{O}$ & $\begin{array}{l}15.67 \\
15.44\end{array}$ & $\begin{array}{l}24.22 \\
15.44\end{array}$ & \\
\hline $\mathrm{ZnO}+\mathrm{EtCH}_{2} \mathrm{OH}+\mathrm{H}_{2} \mathrm{O}$ & $\begin{array}{l}\mathrm{CH}(\mathrm{OH}) \mathrm{Et} \\
\mathrm{OH}\end{array}$ & $\mathrm{H}_{2} \mathrm{O}$ & $\begin{array}{l}15.72 \\
15.51\end{array}$ & $\begin{array}{l}24.24 \\
15.51\end{array}$ & \\
\hline $\mathrm{ZnO}+\mathrm{BuOH}+\mathrm{H}_{2} \mathrm{O}$ & $\begin{array}{l}{ }^{\circ} \mathrm{CH}(\mathrm{OH}) \mathrm{CH}_{2} \mathrm{Et} \\
\cdot \mathrm{OH}\end{array}$ & $\mathrm{H}_{2} \mathrm{O}$ & $\begin{array}{l}15.68 \\
15.45\end{array}$ & $\begin{array}{l}24.32 \\
15.45\end{array}$ & \\
\hline $\begin{array}{l}\mathrm{ZnO}+\mathrm{Na}_{2} \mathrm{SO}_{3}+\mathrm{H}_{2} \mathrm{O} \\
\mathrm{ZnO}+\mathrm{Na}_{2} \mathrm{C}_{2} \mathrm{O}_{4}+\mathrm{H}_{2} \mathrm{O}\end{array}$ & $\begin{array}{l}\mathrm{SO}_{3}^{-} \\
\mathrm{CO}_{2}^{-} \\
\cdot \mathrm{OH}^{2}\end{array}$ & $\begin{array}{l}\mathrm{H}_{2} \mathrm{O} \\
\mathrm{H}_{2} \mathrm{O}\end{array}$ & $\begin{array}{l}14.41 \\
15.69 \\
15.61\end{array}$ & $\begin{array}{l}19.11 \\
24.60 \\
15.61\end{array}$ & \\
\hline $\mathrm{ZnO}+\mathrm{CH}_{3} \mathrm{CO}_{2} \mathrm{Na}+\mathrm{H}_{2} \mathrm{O}$ & $\begin{array}{l}\mathrm{CH}_{2} \mathrm{CO}_{2}^{-}\left(\mathrm{CH}_{3}\right) \\
\mathrm{OH}\end{array}$ & $\mathrm{H}_{2} \mathrm{O}$ & $\begin{array}{l}15.43 \\
15.46\end{array}$ & $\begin{array}{l}26.16 \\
15.46\end{array}$ & \\
\hline $\mathrm{ZnO}+\mathrm{CF}_{3} \mathrm{CO}_{2} \mathrm{Na}+\mathrm{H}_{2} \mathrm{O}$ & $\begin{array}{l}\mathrm{CO}_{2}^{-} \\
\mathrm{OH}^{-}\end{array}$ & $\mathrm{H}_{2} \mathrm{O}$ & $\begin{array}{l}15.74 \\
15.71\end{array}$ & $\begin{array}{l}24.40 \\
15.71\end{array}$ & \\
\hline $\mathrm{ZnO}+\mathrm{CH}_{3} \mathrm{CO}_{2} \mathrm{H}+\mathrm{H}_{2} \mathrm{O}$ & $\begin{array}{l}\mathrm{CH}_{2} \mathrm{CO}_{2} \mathrm{H}\left(\mathrm{CH}_{3}\right) \\
\cdot \mathrm{COCH}_{3} \\
\cdot \mathrm{COCH}_{3}\end{array}$ & $\begin{array}{l}\mathrm{H}_{2} \mathrm{O} \\
\mathrm{C}_{6} \mathrm{H}_{6}\end{array}$ & $\begin{array}{l}16.08 \\
14.73 \\
12.94\end{array}$ & $\begin{array}{l}26.75 \\
16.23 \\
14.37\end{array}$ & \\
\hline $\mathrm{DBPO}^{\mathrm{c}}$ & $\begin{array}{l}\mathrm{OBu}^{t} \\
\mathrm{OH}\end{array}$ & $\mathrm{C}_{6} \mathrm{H}_{6}$ & $\begin{array}{l}13.04 \\
13.50\end{array}$ & $\begin{array}{r}4.08 \\
13.50\end{array}$ & $1.34(1 \mathrm{H})$ \\
\hline $\mathrm{DBPO}+\mathrm{EtBr}$ & $\begin{array}{l}\mathrm{OBu}^{t} \\
\mathrm{OH}\end{array}$ & $\mathrm{C}_{6} \mathrm{H}_{6}$ & $\begin{array}{l}13.12 \\
13.56\end{array}$ & $\begin{array}{r}4.09 \\
13.56\end{array}$ & $1.25(1 \mathrm{H})$ \\
\hline $\begin{array}{l}\mathrm{PhNHNH}_{2}{ }^{\mathrm{d}} \\
\mathrm{ZnO}+\mathrm{THF}^{2}+\mathrm{H}_{2} \mathrm{O}\end{array}$ & $\begin{array}{l}\mathrm{C}_{6} \mathrm{H}_{5} \\
\cdot \mathrm{CH}\left(\mathrm{CH}_{2}\right)_{3} \mathrm{O} \\
\end{array}$ & $\begin{array}{l}\mathrm{C}_{6} \mathrm{H}_{6} \\
\mathrm{H}_{2} \mathrm{O}\end{array}$ & $\begin{array}{l}14.10 \\
15.48\end{array}$ & $\begin{array}{l}23.06 \\
22.99\end{array}$ & \\
\hline $\mathrm{ZnO}+\mathrm{CH}_{3} \mathrm{CN}+\mathrm{H}_{2} \mathrm{O}$ & $\begin{array}{l}\cdot \mathrm{OH} \\
\cdot \mathrm{CH}_{2} \mathrm{CN} \\
\cdot \mathrm{OH}^{2}\end{array}$ & $\mathrm{H}_{2} \mathrm{O}$ & $\begin{array}{l}15.01 \\
14.57 \\
15.18\end{array}$ & $\begin{array}{r}15.01 \\
7.39 \\
15.18\end{array}$ & \\
\hline $\begin{array}{l}\mathrm{BP}^{\mathrm{e}}+\mathrm{CH}_{3} \mathrm{OH} \\
\mathrm{CH}_{3} \mathrm{MgI}\end{array}$ & $\begin{array}{l}\mathrm{CH}_{2} \mathrm{OH} \\
\mathrm{CH}_{3}\end{array}$ & $\begin{array}{l}\mathrm{C}_{6} \mathrm{H}_{6} \\
\mathrm{C}_{6} \mathrm{H}_{6}\end{array}$ & $\begin{array}{l}13.65 \\
12.74\end{array}$ & $\begin{array}{l}5.90 \\
4.35\end{array}$ & \\
\hline
\end{tabular}

Table I. ESR hyperfine splitting constants of nitrone $\mathbf{4}$ spin adducts $^{\mathrm{a}}$.

\footnotetext{
a The splitting constants are given in gauss; ${ }^{\mathrm{b}}$ photolysis with a $200 \mathrm{~W}$ high pressure mercury vapor lamp; c di-tert-butylperoxide; d complexed with di-benzo-C-24-O-8; e benzophenone.
} 

spectrum.

$$
\begin{aligned}
& \mathrm{ZnO}^{+}+\mathrm{RCH}_{2} \mathrm{OH} \rightarrow \mathrm{ZnO}+\mathrm{R} \dot{\mathrm{C}} \mathrm{HOH}+\mathrm{H}^{+} \\
& \mathrm{OH}^{-}+\mathrm{RCH}_{2} \mathrm{OH} \rightarrow \mathrm{R} \dot{\mathrm{C}} \mathrm{HOH}+\mathrm{H}_{2} \mathrm{O}
\end{aligned}
$$

The larger $a_{\mathrm{N}}$ and $a_{\mathrm{H}}^{\beta}$ values for the hydroxyalkyl spin adducts are probably due to an increase in spin density on the nitroxyl nitrogen atom and a decrease in the $\beta-\mathrm{CH}$ dihedral angle because of the intramolecular hydrogen bonding $[14,27]$ as illustrated (6-9). In addition, the two kinds of generated radicals, i.e., hydroxyl and hydroxyalkyl radicals, were trapped within the same solution by $\mathbf{4}$ and distinct EPR spectra were observed while DMPO can scavenge hydroxyl and hydroxyalkyl radicals only in aqueous methanol and $n$-propanol cases at the same conditions (hfsc, given in Table II). These prove the nitrone $\mathbf{4}$ is suitable for the milti-radical system.

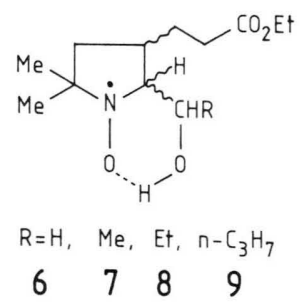

With the nitrone 4, the inorganic radicals $\mathrm{SO}_{3}^{-}$ produced by photolysis of $\mathrm{ZnO}+\mathrm{Na}_{2} \mathrm{SO}_{3}$ in water (eq. (8)), and $\dot{\mathrm{CO}}_{2}^{-}$generated from $\mathrm{ZnO}+$ $\mathrm{Na}_{2} \mathrm{C}_{2} \mathrm{O}_{4}$ in water (eq. (9)) and from $\mathrm{ZnO}+$ $\mathrm{CF}_{3} \mathrm{CO}_{2} \mathrm{Na}$ in water (eq. (10)) have been trapped.

$\mathrm{ZnO}^{+}\left(\mathrm{OH}^{-}\right)+\mathrm{SO}_{3}^{2-} \rightarrow \mathrm{ZnO}\left(\mathrm{OH}^{-}\right)+\dot{\mathrm{SO}}_{3}^{-}$ scavenged by 4 to offer a doublet of triplet of EPR

$\mathrm{ZnO}^{+}\left(\mathrm{OH}^{-}\right)+\mathrm{C}_{2} \mathrm{O}_{4}^{2-} \rightarrow$

$\mathrm{ZnO}\left(\mathrm{OH}^{-}\right)+\mathrm{CO}_{2}+\dot{\mathrm{CO}}_{2}^{-}$

$\mathrm{OH}^{-}+\mathrm{CF}_{3} \mathrm{CO}_{2}^{-} \rightarrow \mathrm{HOCF}_{3}+\dot{\mathrm{CO}_{2}^{-}}$

According to EPR spectrum, photolysis of zinc oxide in aqueous acetic acid in the presence of $\mathbf{4}$ generates at least two kinds of spin adducts, one is acetyl radical adduct $\left(a_{\mathrm{N}}=14.73 \mathrm{G}, a_{\mathrm{H}}^{\beta}=16.23 \mathrm{G}\right)$ and the other is $\dot{\mathrm{C}} \mathrm{H}_{2} \mathrm{CO}_{2} \mathrm{H}$ and/or $\dot{\mathrm{C}} \mathrm{H}_{3}$ radical adduct $\left(a_{\mathrm{N}}=16.08 \mathrm{G}, a_{\mathrm{H}}^{\beta}=26.75 \mathrm{G}\right)$. There are two possible approaches by which the acetyl adduct is resulted. The first is direct addition of acetyl radical (eq. $(11,12))$ to nitrone 4 . The second is the rapid decomposition of the acetoxy spin adduct of 4 as the decomposition of the acetoxy-DMPO adduct [28].

$$
\begin{aligned}
& 2 \mathrm{ZnO}^{+}\left(\mathrm{OH}^{*}\right)+2 \mathrm{CH}_{3} \mathrm{COOH} \rightarrow \\
& 2 \mathrm{ZnO}\left(\mathrm{OH}^{-}\right)+\dot{\mathrm{C}} \mathrm{H}_{2} \mathrm{COOH}+\mathrm{CH}_{3} \mathrm{CO}_{2}+2 \mathrm{H}^{+} \\
& 2 \mathrm{CH}_{3} \mathrm{COO} \rightarrow \mathrm{CH}_{3} \mathrm{CO}+\dot{\mathrm{C}} \mathrm{H}_{3}+\mathrm{CO}_{2}+[\mathrm{O}]
\end{aligned}
$$

The acetyl adduct of nitrone $\mathbf{4}$ is so stable, lifetime $>60 \mathrm{~min}$, that the aminoxyl radical can be extracted from the aqueous solution to benzene and the $a_{\mathrm{N}}$ and $a_{\mathrm{H}}^{\beta}$ values are sensitive to the solvent polarity.

The nitrone $\mathbf{4}$ also can trap phenyl and 2-tetrahydrofuranyl radicals, and their hfs constants are usually larger than these of the corresponding DMPO adducts [14]. But the $a_{\mathrm{H}}^{\beta}$ values of cyanomethyl and methyl radical adducts of nitrone $\mathbf{4}$ are abnormally small. Such phenomenon

\begin{tabular}{|c|c|c|c|}
\hline Source $^{b}$ & Radical addend & $a_{\mathrm{N}}$ & $a_{\mathrm{H}}^{\beta}$ \\
\hline $\mathrm{ZnO}+\mathrm{H}_{2} \mathrm{O}$ & $\dot{\mathrm{OH}}$ & 14.90 & 14.90 \\
\hline $\mathrm{ZnO}+\mathrm{CH}_{3} \mathrm{OH}+\mathrm{H}_{2} \mathrm{O}$ & $\begin{array}{l}\dot{\mathrm{C}} \mathrm{H}_{2} \mathrm{OH} \\
\dot{\mathrm{O}} \mathrm{H}\end{array}$ & $\begin{array}{l}15.90 \\
14.95\end{array}$ & $\begin{array}{l}22.58 \\
14.95\end{array}$ \\
\hline $\mathrm{ZnO}+\mathrm{EtOH}+\mathrm{H}_{2} \mathrm{O}$ & $\dot{\mathrm{C}} \mathrm{H}(\mathrm{OH}) \mathrm{CH}_{3}$ & 15.85 & 22.96 \\
\hline $\mathrm{ZnO}+\mathrm{EtCH}_{2} \mathrm{OH}^{2}+\mathrm{H}_{2} \mathrm{O}$ & $\begin{array}{l}\dot{\mathrm{C}} \mathrm{H}(\mathrm{OH}) \mathrm{Et} \\
\dot{\mathrm{OH}}\end{array}$ & $\begin{array}{l}15.90 \\
14.78\end{array}$ & $\begin{array}{l}23.19 \\
14.78\end{array}$ \\
\hline \multirow{8}{*}{$\begin{array}{l}\mathrm{ZnO}+\mathrm{BuOH}+\mathrm{H}_{2} \mathrm{O} \\
\mathrm{ZnO}+\mathrm{HOCH}_{2} \mathrm{CH}_{2} \mathrm{OH}+\mathrm{H}_{2} \mathrm{O} \\
\mathrm{ZnO}+\mathrm{Na}_{2} \mathrm{C}_{2} \mathrm{O}_{4}+\mathrm{H}_{2} \mathrm{O} \\
\mathrm{ZnO}+\mathrm{Na}_{2} \mathrm{SO}_{3}+\mathrm{H}_{2} \mathrm{O} \\
\mathrm{ZnO}+\mathrm{CH}_{3} \mathrm{CO}_{2} \mathrm{Na}+\mathrm{H}_{2} \mathrm{O} \\
\mathrm{ZnO}+\mathrm{CF}_{3} \mathrm{CO}_{2} \mathrm{Na}+\mathrm{H}_{2} \mathrm{O} \\
\mathrm{ZnO}+\mathrm{THF}+\mathrm{H}_{2} \mathrm{O}\end{array}$} & $\mathrm{C} H(O H) \mathrm{CH}_{2} \mathrm{Et}$ & 15.93 & 23.38 \\
\hline & $\dot{\mathrm{C}} \mathrm{H}(\mathrm{OH}) \mathrm{CH}_{2}^{2} \mathrm{OH}$ & 15.84 & 23.22 \\
\hline & $\dot{\mathrm{C}} \mathrm{O}_{2}^{-}$ & 15.71 & 18.76 \\
\hline & $\mathrm{S}_{3}^{-}$ & 14.44 & 16.22 \\
\hline & $\dot{\mathrm{C}} \mathrm{H}_{2} \mathrm{CO}_{2}^{-}\left(\dot{\mathrm{C}} \mathrm{H}_{3}\right)$ & 15.93 & 22.58 \\
\hline & $\mathrm{CO}_{2}^{2}$ & 15.65 & 18.76 \\
\hline & $\dot{\mathrm{C}} \mathrm{H}^{2}\left(\mathrm{CH}_{2}\right)_{3} \mathrm{O}$ & 15.71 & 19.59 \\
\hline & $\dot{\mathrm{OH}}$ & 14.80 & 14.80 \\
\hline
\end{tabular}
was also found when 3,3,5,5-tetrasubstituted DMPO analogues trapped 2-cyano-2-propyl radicals in organic solvent [17]. As given in Table I, the hfs constants of hydroxymethyl adducts of $\mathbf{4}$ are

Table II. EPR hyperfine splitting constants of DMPO spin adducts in water ${ }^{\mathrm{a}}$.

a The splitting constants are given in gauss; ${ }^{\mathrm{b}}$ photolysis with a $200 \mathrm{~W}$ high pressure mercury vapor lamp. 
$15.86 \mathrm{G}$ for nitrogen splitting and $25.58 \mathrm{G}$ for $\beta$-hydrogen splitting in water, but 13.65 and $5.90 \mathrm{G}$ in benzene. It has been reported that $t$-BuO-DMPÓ nitroxides showed $a_{\mathrm{H}}^{\beta}$ value $8.16 \mathrm{G}$ in benzene and $16.0 \mathrm{G}$ in water [29], and HO-TMPÓ adducts showed $a_{\mathrm{H}}^{\beta}$ value $7.2 \mathrm{G}$ in acetonitrile and $16.6 \mathrm{G}$ in water [17]. In order to scavenge ethyl radical, the benzene solution of DBPO mixed with bromoethane in the presence of $\mathbf{4}$ was irradiated and the ethyl spin adduct was not detected, but the tert-butoxy spin adduct and hydroxyl radical adduct were observed. The reason is probably that the tert-butoxy-trapping rate is much faster than the rate of bromine atom transfer reaction between tert-butoxy and bromoethane.

As DMPO radical adducts', hfs constants of nitrone 4 radical adducts are sensitive to radical addenda. For example, the $a_{\mathrm{H}}^{\beta}$ values for $a$-hydroxycarbon and $\dot{\mathrm{CO}}_{2}^{-}$spin adducts are between $25.58 \mathrm{G}$ and $24.22 \mathrm{G}$, these for $a$-carboxycarbon radical adducts are 26.16$26.75 \mathrm{G}$, and that for acetyl adduct is $16.23 \mathrm{G}$ in aqueous solution. For O-centered radicals, the $a_{\mathrm{H}}^{\beta}$ values are much smaller, $4.08-4.09 \mathrm{G}$ for tert-butoxy adduct, and $13.50-13.56 \mathrm{G}$ for hydroxyl adduct in benzene solution.

In order to clarify the relative spin trapping abilities of nitrone $\mathbf{4}$ and DMPO further, several radical systems were investigated when the two traps were present in a same solution. Photolysis of zinc oxide dispersion in water in the presence of $7.3 \times 10^{-3} \mathrm{M}$ DMPO and $7.1 \times 10^{-3} \mathrm{M}$ nitrone 4 affords only one spin adduct of which hfs constants are $15.60 \mathrm{G}$ for $a_{\mathrm{N}}$ and $15.60 \mathrm{G}$ for $a_{\mathrm{H}}^{\beta}$. By comparison with the hfs constants obtained when nitrone $\mathbf{4}$ and DMPO were used as traps separately, the data are assigned to the hfs constants of the hydroxyl radical adduct of nitrone 4 instead of DMPO because of the closeness of $15.60 \mathrm{G}$ to $15.53 \mathrm{G}$ for nitrone $\mathbf{4}$ hydroxyl adduct. When zinc oxide dispersion in the mixture of water and methanol containing $6.8 \times 10^{-3} \mathrm{M}$ DMPO and $6.6 \times 10^{-3} \mathrm{M}$ nitrone 4 was irradiated, three radical adducts were detected, $15.84 \mathrm{G}$ of $a_{\mathrm{N}}$ and $22.58 \mathrm{G}$ of $a_{\mathrm{H}}^{\beta}$ for $\mathrm{HOCH}_{2}-$ DMPÓ adduct, $15.71 \mathrm{G}$ of $a_{\mathrm{N}}$ and $25.57 \mathrm{G}$ of $a_{\mathrm{H}}^{\beta}$ for $\mathrm{HOCH}_{2}-4$ adduct, and $15.80 \mathrm{G}$ of $a_{\mathrm{N}}$ and $a_{\mathrm{H}}^{\beta}$ for HO-4 adduct. The intensities of $\mathrm{HOCH}_{2}$ DMPO adduct EPR signals are much stronger than these of $\mathrm{HOCH}_{2}-\mathbf{4}$ EPR signals (height: height, $c a$. 5.3:1). For zinc oxide dispersion in water and ethanol, two radical adducts were observed, $15.90 \mathrm{G}$ of $a_{\mathrm{N}}$ and $23.03 \mathrm{G}$ of $a_{\mathrm{H}}^{\beta}$ for $\mathrm{CH}_{3} \mathrm{CH}(\mathrm{OH})$-DMPO adduct, and $15.48 \mathrm{G}$ of $a_{\mathrm{N}}$ and $a_{\mathrm{H}}^{\beta}$ for HO-4 adduct. Other radical systems such as $\mathrm{ZnO}+n-\mathrm{PrOH}+\mathrm{H}_{2} \mathrm{O}, \mathrm{ZnO}+n-\mathrm{BuOH}+$ $\mathrm{H}_{2} \mathrm{O}, \mathrm{ZnO}+\mathrm{THF}+\mathrm{H}_{2} \mathrm{O}, \mathrm{ZnO}+\mathrm{Na}_{2} \mathrm{C}_{2} \mathrm{O}_{4}+\mathrm{H}_{2} \mathrm{O}$ and $\mathrm{ZnO}+\mathrm{Na}_{2} \mathrm{SO}_{3}+\mathrm{H}_{2} \mathrm{O}$ in the presence of nitrone 4 and DMPO were also examined and the competing spin trapping results are collected in Table III. These results indicate that the ability

\begin{tabular}{|c|c|c|c|c|}
\hline Source $^{b}$ & $a_{\mathrm{N}}$ & $a_{\mathrm{H}}^{\beta}$ & $\begin{array}{l}\text { Radical } \\
\text { trapped } \\
\text { by nitrone } \mathbf{4}^{\mathrm{c}}\end{array}$ & $\begin{array}{l}\text { Radical } \\
\text { trapped } \\
\text { by DMPOc }\end{array}$ \\
\hline $\mathrm{ZnO}+\mathrm{H}_{2} \mathrm{O}$ & 15.60 & 15.60 & $\dot{\mathrm{O} H}$ & \\
\hline \multirow{2}{*}{$\mathrm{ZnO}+\mathrm{CH}_{3} \mathrm{OH}+\mathrm{H}_{2} \mathrm{O}$} & 15.80 & 15.80 & & \\
\hline & $\begin{array}{l}15.71 \\
15.84\end{array}$ & $\begin{array}{l}25.57^{\mathrm{d}} \\
22.58^{\mathrm{d}}\end{array}$ & $\mathrm{CH}_{2} \mathrm{OH}$ & $\dot{\mathrm{C}} \mathrm{H}, \mathrm{OH}$ \\
\hline \multirow[t]{2}{*}{$\mathrm{ZnO}+\mathrm{EtOH}+\mathrm{H}_{2} \mathrm{O}$} & 15.48 & 15.48 & $\dot{\mathrm{O} H}$ & \\
\hline & $\begin{array}{l}15.90 \\
15.49\end{array}$ & 23.03 & & $\mathrm{CH}(\mathrm{OH}) \mathrm{CH}_{3}$ \\
\hline $\mathrm{ZnO}+\mathrm{EtCH}_{2} \mathrm{OH}+\mathrm{H}_{2} \mathrm{O}$ & $\begin{array}{l}15.49 \\
15.90\end{array}$ & $\begin{array}{l}15.49 \\
23.47\end{array}$ & $\mathrm{OH}$ & $\dot{\mathrm{C}} \mathrm{H}(\mathrm{OH}) \mathrm{Et}$ \\
\hline $\mathrm{ZnO}+\mathrm{BuOH}+\mathrm{H}_{2} \mathrm{O}$ & $\begin{array}{l}15.50 \\
15.90\end{array}$ & $\begin{array}{l}15.50 \\
23.54\end{array}$ & ÖH & $\dot{\mathrm{C}} \mathrm{H}(\mathrm{OH}) \mathrm{CH} \mathrm{Ft}$ \\
\hline \multirow[t]{2}{*}{$\mathrm{ZnO}+\mathrm{THF}+\mathrm{H}_{2} \mathrm{O}$} & $\begin{array}{l}15.90 \\
15.05 \\
15.90\end{array}$ & $\begin{array}{l}23.04 \\
15.05 \\
23.09^{\mathrm{e}}\end{array}$ & $\stackrel{\dot{\mathrm{O}} \mathrm{H}}{\mathrm{C}} \mathrm{H}\left(\mathrm{CH}_{2}\right)_{3} \mathrm{O}$ & 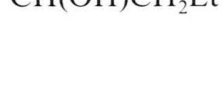 \\
\hline & 15.68 & $19.21^{\mathrm{e}}$ & & $\dot{\mathrm{C}} \mathrm{H}\left(\mathrm{CH}_{2}\right)_{3} \mathrm{O}$ \\
\hline \multirow[t]{2}{*}{$\mathrm{ZnO}+\mathrm{Na}_{2} \mathrm{C}_{2} \mathrm{O}_{4}+\mathrm{H}_{2} \mathrm{O}$} & $\begin{array}{l}15.52 \\
15.65\end{array}$ & $\begin{array}{l}15.52^{\mathrm{f}} \\
24.61^{\mathrm{f}}\end{array}$ & $\stackrel{\dot{\mathrm{O}} \mathrm{H}}{\mathrm{C} \mathrm{O}_{2}^{-}}$ & \\
\hline & 15.71 & $18.76^{\mathrm{f}}$ & & $\mathrm{CO}_{2}^{-}$ \\
\hline \multirow[t]{2}{*}{$\mathrm{ZnO}+\mathrm{Na}_{2} \mathrm{SO}_{3}+\mathrm{H}_{2} \mathrm{O}$} & 14.44 & $19.08^{\mathrm{g}}$ & $\mathrm{SO}_{3}^{-}$ & \\
\hline & 14.47 & $16.22^{\mathrm{g}}$ & & $\mathrm{NO}_{3}$ \\
\hline
\end{tabular}

Table III. The competing spin trapping results of nitrone $\mathbf{4}$ and DMPO in water ${ }^{\mathrm{a}}$.

\footnotetext{
a The splitting constants are given in gauss; ${ }^{b}$ photolysis with a $200 \mathrm{~W}$ high pressure mercury vapor lamp; ${ }^{c}$ concentrations of nitrone $\mathbf{4}$ in various solutions are from $6.6 \times 10^{-3} \mathrm{M}$ to $7.1 \times 10^{-3} \mathrm{M}$ while these of DMPO are from $6.8 \times 10^{-3} \mathrm{M}$ to $7.3 \times 10^{-3} \mathrm{M}$; ${ }^{\mathrm{d}}$ the height ratio of hydroxymethyl adduct signals of DMPO to that of nitrone 4 is $c a$. $5.3: 1$; e the height ratio of 2-tetrahydrofuranyl adduct signals of DMPO to that of nitrone $\mathbf{4}$ is $c a$. $1.5: 1$; ${ }^{\mathrm{f}}$ see Fig. 2; $\mathrm{g}$ the height ratio of $\mathrm{SO}_{3}^{-}$adduct signals of DMPO to that of nitrone 4 is ca. $4.8: 1$.
} 


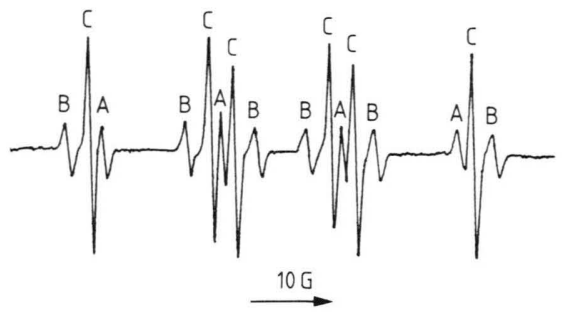

Fig. 2. EPR spectrum recorded when photolysis of $35 \mathrm{mg}$ zinc oxide, $5 \mathrm{mg}$ sodium oxalate, $7.1 \times 10^{-3} \mathrm{M}$ nitrone 4 and $7.3 \times 10^{-3} \mathrm{M}$ DMPO in $0.5 \mathrm{ml}$ of water, (A) hydroxyl spin adduct of nitrone 4, (B) $\dot{\mathrm{CO}}_{2}^{-}$spin adduct of nitrone 4 , (C) $\mathrm{CO}_{2}^{-}$spin adduct of DMPO.

of DMPO to trap hydroxyalkyl radicals, 2-tetrahydrofuranyl radical, $\dot{\mathrm{CO}}_{2}^{-}$and $\dot{\mathrm{SO}}_{3}^{-}$radicals is better than that of nitrone $\mathbf{4}$, but the activity of nitrone $\mathbf{4}$ to scavenge hydroxyl radical is greater than that of DMPO. Thus, mono-substitution on $\mathrm{C}_{3}$ ring position probably increase the spin trapping selectivity of substituted 1-pyrroline $\mathrm{N}$-oxide for hydroxyl radical. Fig. 2 is an EPR spectrum acquired from photolysis of zinc oxide dispersed in aqueous solution of $\mathrm{Na}_{2} \mathrm{C}_{2} \mathrm{O}_{4}$ in the presence of $7.3 \times 10^{-3} \mathrm{M}$ DMPO and $7.1 \times 10^{-3} \mathrm{M}$ nitrone 4 . The half life-times of ${ }^{-} \mathrm{O}_{2} \mathrm{C}$-DMPO adduct, ${ }^{-} \mathrm{O}_{2} \mathrm{C}$ 4 adduct and HO-4 adduct are respectively $c a$. $50 \mathrm{~min}, 59 \mathrm{~min}$ and $85 \mathrm{~min}$ upon EPR study results. So nitrone $\mathbf{4}$ spin adducts are relatively persistent.

\section{Spin trapping stereochemistry}

The significantly different ${ }^{1} \mathrm{H}$ NMR values of nitrone 4 5,5-dimethyl protons indicate the substitution group on the 3-carbon has different influences on the two methyl groups and the nitrone should exist in a preferential conformation in a solution. Likewise, the EPR spectrum of 2,2-dimethyl-4-(3-hydroxypropyl)pyrrolidinyl-1-oxyl aminoxyl radical (5), which was obtained by reduction of $\mathbf{4}$ with sodium borohydride similar to the methods reported [13,30-32] and following auto-oxidation in the presence of air (eq. (13)),

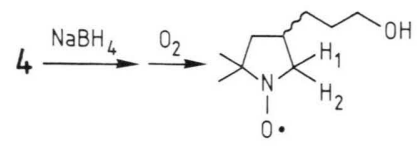

showed that the two $a_{\mathrm{H}}^{\beta}$ values are equal to $14.58 \mathrm{G}$ and $23.29 \mathrm{G}$ respectively $\left(\Delta a_{\mathrm{H}}^{\beta}=8.71 \mathrm{G}\right)$, and so the two $\beta$-hydrogens are dramatically magnetically non-equivalent. This is due to the orientation of one $\beta$-hydrogen at the pseudoequatorial position of a preferential conformation with respect to the semi-occupied $p$-orbital of the aminoxyl nitrogen is different from that of the other $\beta$-hydrogen at the pseudoaxial position as presented in the following two possible conformations $\left(\mathbf{5}^{\prime}, \mathbf{5}^{\prime \prime}\right)$ of

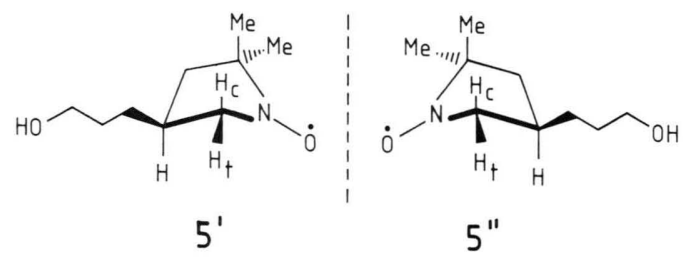

which the EPR spectra should be same with each other (Fig. $3 \mathrm{~A}$ ). It is noticeable that the reduction of nitrone 4 with excess sodium borohydride at room temperature gives 2,2-dimethyl-4-(3-hydroxypropyl)pyrrolidinyl-1-hydroxy instead of 2,2-dimethyl-4-(2-ethoxycarbonylethyl)pyrrolidinyl-

1-hydroxy according to the IR spectrum of reduced product. We have previously reported that 5-alkyl-5-methylpyrrolidinyl-1-oxyl nitroxides employ two non-equivalent $\beta$-hydrogens $[12,13]$. In comparison, DMPO was also reduced and autooxidized to give 2,2-dimethylpyrrolidinyl-1-oxyl

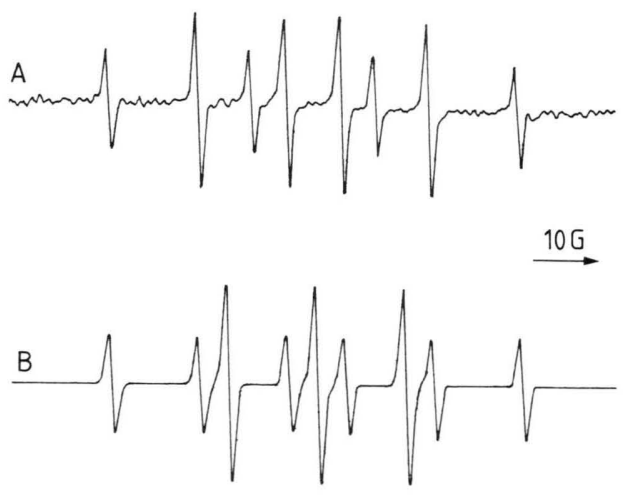

Fig. 3. EPR spectra of (A) aminoxyl radical 5 in benzene solution indicating non-equivalence of two $\beta$-hydrogens, $a_{\mathrm{N}}=14.58 \mathrm{G}, a_{\mathrm{H}}^{\beta}=14.58 \mathrm{G}, a_{\mathrm{H}_{2}}^{\beta}=23.29 \mathrm{G}$; $(\mathrm{B})$ aminoxyl radical DTPO in benzene solution indicating equivalence of two $\beta$-hydrogens, $a_{\mathrm{N}}=14.31 \mathrm{G}, a_{\mathrm{H}}^{\beta}=19.04 \mathrm{G}$ $(2 \mathrm{H})$. 
(DTPO) nitroxide radical of which EPR spectrum showed hfs constants of two $\beta$-hydrogens are $19.04 \mathrm{G}$ respectively, indicating the equivalence of the two $\beta$-hydrogens (Fig. $3 \mathrm{~B}$ ).

Owing to the presence of the chiral 3-carbon, there are two possible spin trapping approaches, i.e., the radical trans-addition and cis-addition. If the nitrone cannot stereoselectively or stereospecifically scavenge transient free radical, trapping one radical should give at least four possible spin adduct isomers as illustrated in Scheme 2. The $s y n$-isomers of spin adducts should have the same $a_{\mathrm{H}}^{\beta}$ values, the reason of which is that the chemical structural environment for aminoxyl and $\beta$-proton is same with each other between the two isomers, and so were the two anti-isomers. However, the $a_{\mathrm{H}}^{\beta}$ value of the $s y n$-isomers must be different from that of the anti-isomers because the $s y n$-isomers is chemically different from the anti-isomers and the $a_{\mathrm{H}}^{\beta}$ value is very sensitive to the structural difference as reflected in the nitroxide $\mathbf{5}$ and 5-alkyl5-methylpyrrolidinyl-1-oxyls [12, 13]. Therefore, if the spin trapping reaction affords $s y n$-isomers and ant $i$-isomers at the same time, the observed EPR spectrum should show at least two different $a_{\mathrm{H}}^{\beta}$ values. Kotake and co-workers have discovered some diastereomers of $a$-phenyl N-tert-butyl nitrone (PBN) and DMPO spin adducts show different $a_{\mathrm{H}}^{\beta}$ values in some solvents $\left(\Delta a_{\mathrm{H}}^{\beta}<1.0 \mathrm{G}\right)$ [33]. Diastereomers of nitrone 4 spin adducts must have much larger $\Delta a_{\mathrm{H}}^{\beta}$ values because of the presence of two chiral carbon centers within the five-membered ring.

However, when nitrone 4 trapped hydroxyl radical, tert-butoxy radical, phenyl radical, hydroxy-
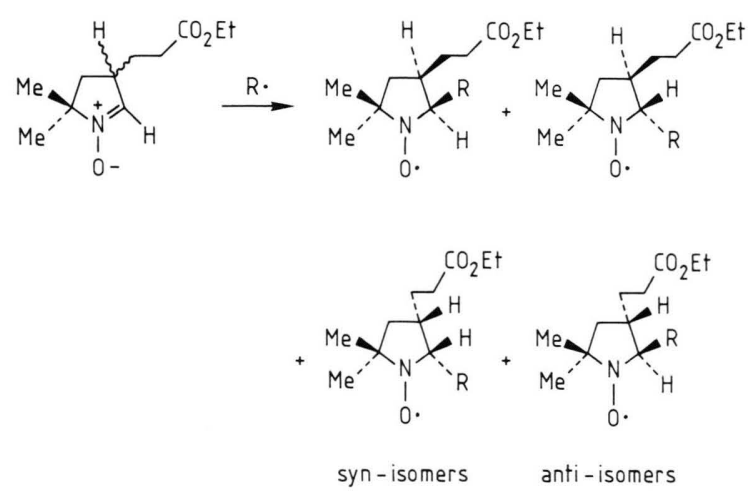

Scheme 2 methyl radical, 1-hydroxyethyl radical, 1-hydroxypropyl radical, 1-hydroxybutyl radical, $\dot{\mathrm{SO}}_{3}^{-}$radical and $\dot{\mathrm{CO}}_{2}^{-}$radical, the EPR spectrum of the corresponding spin adduct showed only one $a_{\mathrm{H}}^{\beta}$ value as DMPO. The results indicate that the spin trapping reactions are most probably plane selective, and the selectivity is so high that the EPR spectrometer can detect only one of the two spin adduct pairs. The nitrone $\mathbf{4}$ should prefer such a structural model that the nitronyl group, 3-carbon, and 5 -carbon are on a same plane, and the 4-methylene is puckered from the 3-(2-ethoxycarbonylethyl) substitution. Because of the hindrance of the 3 -substitution, the transient free radical mentioned above should add to the nitronyl function in the direction trans to the 3-substitution group to afford anti-isomers as illustrated in Scheme 3.

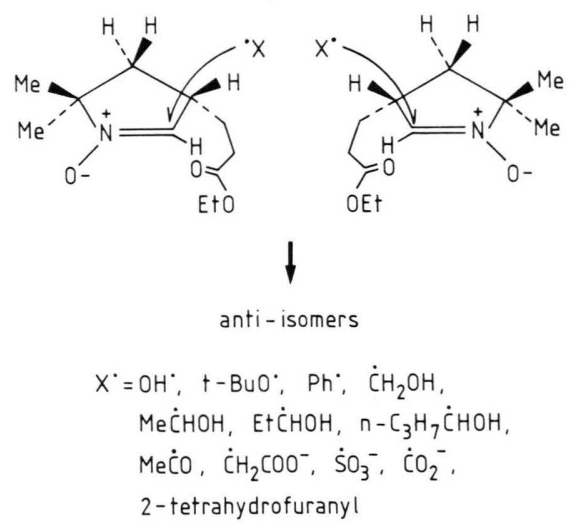

Scheme 3

In conclusion, nitrone $\mathbf{4}$ can trap a series of short-lived free radicals, particularly hydroxyl radical. The spin adducts are very stable, and $a_{\mathrm{H}}^{\beta}$ values are sensitive to individual radical addendum. The spin trapping process is probably plane selective to give trans-adducts.

\section{Experimental Section}

\section{Instrumentation}

Microanalyses were obtained using a HeraeusCHN-Rapid elemental analyser. IR spectra were recorded on a Carl Zeiss Jena Specord-75 spectrometer. Mass spectra were obtained using an AEI MS-50 spectrometer. ${ }^{1} \mathrm{H}$ NMR spectra were determined on a Varian EM-360 $(60 \mathrm{MHz})$ or JEOL 
JNM-FX 100 spectrometers using tetrachloride carbon or deuterochloroform as a solvent and tetramethylsilane as an internal standard. EPR spectra were recorded on a Bruker ESP-300 EPR spectrometer at room temperature. UV spectra were acquired with a HITACHI-340 ultraviolet spectrometer.

\section{Spin trapping procedure}

Zinc oxide powder suspended in distilled water in a $10-\mathrm{ml}$ beaker was dispersed by ultrasound for $10 \mathrm{~min}$. The aqueous dispersion $(0.5 \mathrm{ml})$ containing about $35 \mathrm{mg}$ zinc oxide, $60 \mu \mathrm{l}$ of $0.071 \mathrm{M}$ aqueous solution of 4 or $40 \mu 1$ of $0.11 \mathrm{M}$ DMPO aqueous solution were placed in an EPR tube and deoxygenated. The mixture was then irradiated with a $200 \mathrm{~W}$ high pressure mercury vapor lamp. When trapping a hydroxyalkyl radical, $50 \mu \mathrm{l}$ of the corresponding alcohol was added before deoxygenation. When salts were used for generation of radicals, $5 \mathrm{mg}$ of each salt was added to a tube before deoxygenation and irradiation. DMPO was prepared by the literature procedure [34]. In $100 \mathrm{ml}$ of double-distilled water, $1.7 \mathrm{~g}(15 \mathrm{mmol})$ of DMPO was dissolved. The $0.15 \mathrm{M}$ solution was twicely purified with $2 \times 0.08 \mathrm{~g}$ active charcoal refluxing for $20 \mathrm{~min}$, filtered. The concentration was $0.11 \mathrm{M}$ determined on an UV spectrometer. This DMPO solution all showed no EPR signals without photolysis and after photolysis for $30 \mathrm{~min}$. The $0.071 \mathrm{M}$ nitrone 4 aqueous solution was obtained as the method for preparation of DMPO solution. Any EPR signals were not detected without and after photolysis of nitrone 4 solution.

\section{Preparation of ethyl 4-(2-methyl-2-nitropropyl)- 5-oxopentanoate (3)}

Ester-nitro-aldehyde $\mathbf{3}$ was first prepared according to the procedure used for the preparation of ethyl 4-ethyl-5-oxo-pentanoate in the literature [35]. To a mixture of piperidine $(29.3 \mathrm{~g}, 0.345 \mathrm{~mol})$ and anhydrous $\mathrm{K}_{2} \mathrm{CO}_{3}(10 \mathrm{~g}, 0.072 \mathrm{~mol})$ was added dropwise nitro-aldehyde 1 ( $20 \mathrm{~g}, 0.138 \mathrm{~mol})$ for $25 \mathrm{~min}$ at $2{ }^{\circ} \mathrm{C}$, and stirred overnight. Ether $(300 \mathrm{ml})$ was added, filtered, and evaporated under a reduced pressure to remove excessive piperidine. To a solution of the obtained crude enamine 2 in $100 \mathrm{ml}$ of freshly distilled acetonitrile was added dropwise a solution of ethyl acrylate (18 g, $0.18 \mathrm{~mol}$ ) in $60 \mathrm{ml}$ of dry acetonitrile for $60 \mathrm{~min}$ at $2{ }^{\circ} \mathrm{C}$, stirred for additional $5 \mathrm{~h}$ at room temperature. Then, the reaction mixture was refluxed for $40 \mathrm{~h}$, cooled, and $10 \mathrm{ml}$ of acetic acid in $60 \mathrm{ml}$ of water was added, refluxed for $8 \mathrm{~h}$. After cooling,
$15 \mathrm{~g}$ of sodium chloride was added, and the organic layer was dried over anhydrous sodium sulfate, filtered, evaporated. The residue dissolved in $250 \mathrm{ml}$ of benzene was passed through a short silica gel column to remove black impurities, evaporated and followed by distillation to give $4.75 \mathrm{~g}$ ( $14 \%$ overall yield) of 3 , b. p.: $162-165^{\circ} \mathrm{C} / 0.5 \mathrm{~mm}$ Hg; IR (Neat): 2717, 1717, 1527, $1176 \mathrm{~cm}^{-1} ;{ }^{1} \mathrm{H}$ NMR $\left(\mathrm{CDCl}_{3}\right): \delta 1.24\left(\mathrm{t}, 3 \mathrm{H}, \mathrm{CH}_{3}\right), 1.50(\mathrm{~s}, 3 \mathrm{H}$, $\left.\mathrm{CH}_{3}\right), 1.60\left(\mathrm{~s}, 3 \mathrm{H}, \mathrm{CH}_{3}\right), 1.82-2.02\left(\mathrm{~m}, 2 \mathrm{H}, \mathrm{CH}_{2}\right)$, 2.21-2.68 (m, 5 H, $\left.\mathrm{CH}_{2}, \mathrm{CHCO}, \mathrm{CH}_{2} \mathrm{CO}_{2}\right), 4.06$ $\left(\mathrm{q}, 2 \mathrm{H}, \mathrm{CH}_{2} \mathrm{O}\right), 9.57(\mathrm{~s}, 1 \mathrm{H}, \mathrm{CHO})$.

Preparation of 5,5-dimethyl-3-(2-ethoxycarbonylethyl)-1-pyrroline $\mathrm{N}$-oxide (4)

The procedure used for the preparation of DMPO and its analogues [34] was adapted for the preparation of nitrone $\mathbf{4}$ as following. Zinc dust $(2.76 \mathrm{~g}, 0.038 \mathrm{~mol})$ was added to a solution of $\mathbf{3}$ $(4.65 \mathrm{~g}, 0.019 \mathrm{~mol})$ in $80 \mathrm{ml}$ of $95 \%$ ethanol that had been precooled to $3{ }^{\circ} \mathrm{C}$. Under brisk mechanical stirring, glacial acetic acid $(5.06 \mathrm{~g}, 0.084 \mathrm{~mol})$ in $20 \mathrm{ml}$ of $95 \%$ ethanol was added dropwise for 20 min while maintaining the reaction temperature below $8{ }^{\circ} \mathrm{C}$. The mixture was stirred vigorously for additional $2 \mathrm{~h}$, stored in a refrigerator for $20 \mathrm{~h}$, filtered, washed with $20 \mathrm{ml}$ of ethanol, evaporated. The residue was dissolved in $20 \mathrm{ml}$ of chloroform, stored again in a refrigerator for one day, filtered, evaporated and followed by chromatography on a silica gel column with chloroform as the eluent to give $2,71 \mathrm{~g}(67 \%)$ of a slightly yellowish oil which was further purified by distillation to prepare analytical sample, of which the structure was assigned as 5,5-dimethyl-3-(2-ethoxycarbonylethyl)1-pyrroline $\mathrm{N}$-oxide (4) on the basis of the following data. B. p.: $164-166{ }^{\circ} \mathrm{C} / 1 \mathrm{~mm} \mathrm{Hg}$; $\mathrm{UV}\left(\mathrm{H}_{2} \mathrm{O}\right)$ : $\lambda_{\max }=229 \mathrm{~nm}$; IR (Neat): 3069, 1717, 1567, 1227 , $1173 \mathrm{~cm}^{-1} ;{ }^{1} \mathrm{H}$ NMR $\left(\mathrm{CCl}_{4}\right): \delta 1.24\left(\mathrm{t}, 3 \mathrm{H}, \mathrm{CH}_{3}\right)$, $1.28\left(\mathrm{~s}, 3 \mathrm{H}\right.$, ring $\left.5-\mathrm{CH}_{3}\right), 1.35\left(\mathrm{~s}, 3 \mathrm{H}\right.$, ring $\left.5-\mathrm{CH}_{3}\right)$, $1.60-1.93\left(\mathrm{~m}, 2 \mathrm{H}, \mathrm{CH}_{2}\right), 2.17\left(\mathrm{~d}, 2 \mathrm{H}\right.$, ring $\left.\mathrm{CH}_{2}\right)$, $2.31\left(\mathrm{t}, 2 \mathrm{H}, \mathrm{CH}_{2} \mathrm{CO}_{2}\right), 2.97(\mathrm{~m}, 1 \mathrm{H}$, ring $3-\mathrm{CH})$, $4.00\left(\mathrm{q}, 2 \mathrm{H}, \mathrm{CH}_{2} \mathrm{O}\right), 6.59(\mathrm{~d}, 1 \mathrm{H}, \mathrm{CH}=\mathrm{N})$; MS (EI, rel. int. \%): $m / z 213\left(\mathrm{M}^{+}, 50\right), 198\left(\mathrm{M}-\mathrm{CH}_{3}, 21\right)$, 168 (M-OEt, 43), 126 (100), 125 (26), 112 (23), $110(21)$.

$$
\begin{array}{llll}
\mathrm{C}_{11} \mathrm{H}_{19} \mathrm{NO}_{3}(213.28) & & \\
\text { Calcd } & \mathrm{C} 61.95 & \mathrm{H} 8.98 & \text { N } 6.57 \\
\text { Found } & \mathrm{C} 61.66 & \mathrm{H} 8.41 & \text { N } 6.81
\end{array}
$$

$\operatorname{HRMS}(m / z)$ for $\mathrm{C}_{11} \mathrm{H}_{19} \mathrm{NO}_{3}$

Calcd 213.1365

Found 213.1363 
Reduction of 5,5-dimethyl-3-(2-ethoxycarbonylethyl)-1-pyrroline $\mathrm{N}$-oxide (4)

Nitrone $4(0.06 \mathrm{~g}, 0.28 \mathrm{mmol})$ and sodium borohydride $(0.20 \mathrm{~g}, 5.3 \mathrm{mmol})$ in $10 \mathrm{ml}$ of distilled water was standing for two days. The mixture was saturated with sodium chloride, extracted with $2 \times 20 \mathrm{ml}$ of diethyl ether, dried over anhydrous sodium sulfate, filtered, evaporated to give $0.04 \mathrm{~g}$ $(82 \%)$ of clear liquid. IR spectrum indicated that nitronyl group and ester group were all reduced. IR (Neat): 3300 (br., OH), 2927, 2853, 1444, 1356, 1047 (vs., C-O), $1007 \mathrm{~cm}^{-1}$. A small amount of this product was dissolved in $0.5 \mathrm{ml}$ of benzene, measured directly with an EPR spectrometer, and the aminoxyl radical 5 was detected. The hfs con- stants are $a_{\mathrm{N}}=14.58 \mathrm{G}, a_{\mathrm{H}_{1}}^{\beta}=14.58 \mathrm{G}, a_{\mathrm{H}_{2}}^{\beta}=$ $23.29 \mathrm{G}$.

\section{Reduction of 5,5-dimethyl-1-pyrroline $\mathrm{N}$-oxide (DMPO)}

The procedure is as same as that used for reduction of nitrone 4. Yield: $80 \%$; IR (Neat): 3200 $(\mathrm{OH}), 2957,2866,1445,1356 \mathrm{~cm}^{-1}$. DTPO aminoxyl radical was detected within the reduced product because of the auto-oxidization of 2,2-dimethylpyrrolidinyl-1-hydroxy. The hfs constants are $a_{\mathrm{N}}=14.31 \mathrm{G}, a_{\mathrm{H}}^{\beta}=19.04 \mathrm{G}(2 \mathrm{H})$.

We thank the National Natural Science Foundation of China for the financial support of this work.
[1] E. G. Janzen and B. J. Blackburn, J. Am. Chem. Soc. 90, 5909 (1968).

[2] E. G. Janzen and B. J. Blackburn, ibid. 91, 4481 (1969).

[3] E. G. Janzen, Acc. Chem. Res. 4, 31 (1971).

[4] T. Ozawa and A. Hanaki, Chem. Lett. 1987, 1885.

[5] K. P. Madden, H. Taniguchi, and R. W. Fessenden, J. Am. Chem. Soc. 110, 2753 (1988).

[6] T. Ozawa and A. Hanaki, Bull. Chem. Soc. Jpn. 60, 2304 (1987).

[7] G. M. Rosen, B. E. Britigan, M. S. Cohen, S. P. Ellington, and M. J. Barker, Biochim. Biophys. Acta 969, 236 (1988).

[8] P. Graceffa, Biochim. Biophys. Acta 954, 227 (1988).

[9] K. Stolze, D. R. Duling, and R. P. Mason, J. Chem. Soc. Chem. Commun. 1988, 268.

[10] G. Gronchi, P. Courbis, P. Tordo, G. Mousset, and J. Simonet, J. Phys. Chem. 87, 1343 (1983).

[11] E. G. Janzen and G. A. Coulter, J. Am. Chem. Soc. 106, 1962 (1984).

[12] Y.-K. Zhang and G.-Z. Xu, J. Chem. Soc. Chem. Commun. 1988, 1629.

[13] Y.-K. Zhang and G.-Z. Xu, Magn. Reson. Chem. 27, 846 (1989).

[14] E. G. Janzen and J. I.-P. Liu, J. Magn. Reson. 9, $510(1973)$.

[15] D. L. Haire and E. G. Janzen, Can. J. Chem. 60, 1514 (1982)

[16] M. J. Turner, III and G. M. Rosen, J. Med. Chem. 29, 2439 (1986).

[17] P. Barker, A. L. J. Beckwith, W. R. Cherry, and R. Huie, J. Chem. Soc. Perkin Trans. 2 1985, 1147.

[18] G. M. Rosen and M. J. Turner, III, J. Med. Chem. 31, 428 (1988).

[19] E. G. Janzen, R. V. Shetty, and S. M. Kunanec, Can. J. Chem. 59, 756 (1981).
[20] A. Dehnel, D. Griller, and J. M. Kanabus-Kaminska, J. Org. Chem. 53, 1566 (1988).

[21] J. R. Harbour and M. L. Hair, J. Phys. Chem. 83, 652 (1979).

[22] C.-P. Chen, X.-M. Ren, D.-H. Lu, and Y.-K. Zhang, GanGuangKeXue Yu GuangHuaXue, in press.

[23] J. R. Harbour, V. Chow, and J. R. Bolton, Can. J. Chem. 52, 3549 (1974).

[24] P. R. Marriott, M. J. Perkins, and D. Griller, Can. J. Chem. 58, 803 (1980).

[25] E. G. Janzen, D. E. Nutter (Jr.), E. R. Davis, B. J. Blackburn, J. L. Poyer, and P. B. McCay, Can. J. Chem. 56, 2237 (1978).

[26] F. P. Sargent and E. M. Gardy, Can. J. Chem. 54, 275 (1976)

[27] E. G. Janzen and I. G. Lopp, J. Magn. Reson. 7, 107 (1972).

[28] W. A. Pryor, C. K. Govindan, and D. F. Church, J. Am. Chem. Soc. 104, 7563 (1982).

[29] D. L. Haire, U. M. Oehler, P. H. Krygsman, and E. G. Janzen, J. Org. Chem. 53, 4535 (1988).

[30] R. F. C. Brown, V. M. Clark, and S. A. Todd, J. Chem. Soc. 1959, 2105.

[31] A. L. Castelhano, D. Griller, and K. U. Ingold, Can. J. Chem. 60, 1501 (1982).

[32] P. H. Morgan and A. H. Beckett, Tetrahedron 31, 2595 (1975).

[33] Y. Kotake and K. Kuwata, Can. J. Chem. 60, 1610 (1982); Y. Kotake, K. Kuwata, and E. G. Janzen, J. Phys. Chem. 83, 3024 (1979); Y. Kotake and K. Kuwata, Bull. Chem. Soc. Jpn. 54, 394 (1981).

[34] D. L. Haire, J. W. Hiborn, and E. G. Janzen, J. Org. Chem. 51, 4298 (1986).

[35] G. Stork, A. Brizzolara, H. Landesman, J. Szmuszkovicz, and R. Terrell, J. Am. Chem. Soc. 85, 207 (1963). 